\title{
Exploring support needed by home health aides in choosing bathing equipment: New challenges for occupational therapy collaboration
}

\author{
Manon Guay ${ }^{\mathrm{a}, \mathrm{b}, *}$, Mélanie Levasseur $^{\mathrm{a}, \mathrm{b}}$, Sophie Turgeon-Londei ${ }^{\mathrm{b}}$, Marie-France Dubois ${ }^{\mathrm{a}, \mathrm{b}}$ and \\ Johanne Desrosiers ${ }^{\mathrm{a}, \mathrm{b}}$ \\ ${ }^{a}$ Université de Sherbrooke, Sherbrooke, QC, Canada \\ ${ }^{\mathrm{b}}$ Research Center on Aging, Health and Social Services Center, University Institute of Geriatrics of Sherbrooke, \\ Sherbrooke, QC, Canada
}

Received 29 December 2011

Accepted 5 July 2012

\begin{abstract}
.
In Quebec (Canada), home health aides are gradually being involved in choosing bathing equipment for community-dwelling clients with bathing difficulties, a task traditionally performed by occupational therapists.

OBJECTIVE: This article explores the support home health aides want in assuming this clinical task.

PARTICIPANTS: Three home health aides having previously intervened with clients with bathing difficulties.

METHODS: Home health aides were first observed while performing an assessment, followed by an in-depth individual interview. RESULTS: Results indicate that participants wish to be trained to acquire further knowledge about bathing equipment and learn to use a tool that would guide and document their observations. They sought partnership with a designated occupational therapist, who would be available to answer questions and assess clients with a complex clinical situation.

CONCLUSIONS: These results suggest that needs of home health aides are not currently met and highlight clinical as well as organizational implications.
\end{abstract}

Keywords: Skill mix, professional assistant, bath, assistive devices, decision-making

\section{Introduction}

In home-care settings, occupational therapists (OTs) visit community-dwelling older adults facing challenges performing their activities of daily living, with bathing being a common difficulty [1]. Part of what

\footnotetext{
${ }^{*}$ Corresponding author: Manon Guay, Research Center on $\mathrm{Ag}$ ing, Health and Social Services Center, University Institute of Geriatrics of Sherbrooke, 1036 Belvédère sud, Sherbrooke, QC, J1H4C4, Canada. Te1: +1 819821 1170; Fax: +1 819829 7141; E-mail: Manon.Guay@USherbrooke.ca.
}

OTs do is to choose and recommend bathing equipment, such as grab bars and bathing seats, to enhance the client's independence and the safety of both the client and their helper. Unfortunately, home health OTs working in Quebec must deal with service demands that exceed the number of qualified OTs. In fact, even if, in $2007,31 \%$ of the 12,297 Canadian OTs were practicing in Quebec, making it the Canadian province with the highest ratio of OTs per person (i.e. 45 for $100,000)$ [2], Quebec still has a shortage of human resources in home-health settings, which has been documented over the last 20 years $[3,4]$. 
One solution to work organization, albeit controversial, is to assign occupational-therapy service components (such as the clinical task of choosing and recommending bathing equipment) to non-occupational therapists (non-OTs). Actually, the use of skill mix - a flexible combination of human resources - by introducing extended roles and cross-skilling on the interdisciplinary team has been proposed internationally [5-8]. Given the fact that the provincial regulatory board, the Ordre des ergothérapeutes du Québec (OEQ), do not support formal training for occupational therapist assistants, many health-care institutions have gradually involved home health aides (HHAs) in choosing bathroom equipment for community-dwelling clients with bathing difficulties. This approach to organizing and delivering services has elicited controversy [9] because the traditional HHA role is to provide direct assistance to clients according to a treatment plan developed by professionals (often OTs, especially when hygiene is involved). In addition, those choices put pressure on OT professional boundaries, which might modify their scope of practice $[10,11]$.

Nevertheless, some HHAs are currently choosing bathroom equipment for "simple cases," that is, when a visit by an OT is not required for the safety of both the client and assistant during bathing $[12,13]$. According to Cloutier et al. $[11,14,15]$, organizing work in this way has a positive impact on the physical and psychological health of home health aides by recognizing their competency and promoting adaption of their working environment to decrease the risks of them developing musculoskeletal disorders.

This relatively new and original way of organizing and delivering services pertaining to the selection of bathing equipment actually occurs frequently. In a census conducted in 86 health and social services centers (HSSCs) in Quebec, more than half (57\%) of the service-delivery models involved specially trained non-OTs, generally HHAs, in choosing bathing equipment [16]. This trend has gained popularity over the last five years. Estimates indicate that $60 \mathrm{HHAs}$ working in HSSCs are engaged in this clinical task.

Clinical OTs working with HHAs in Quebec are encouraged by their provincial regulatory board to accept this role overlap and are asked to support HHAs in this practice [17]. Little, however, is known about the support HHAs need in choosing the right bathroom equipment. This lack of knowledge has led to a strikingly wide variety of local and probably not evidence-based decisions. In fact, clinical OTs in Quebec provide informal training, lasting from 1 to 40 hours (mean of 8 hours) and have developed at least 52 "in-house" assessment tools to assist non-OTs involved in choosing bathing equipment [16]. Initiatives such as providing training and tools, even if they are soundly based, raise important questions about client security, OT professional responsibility, and work efficiency. Moreover, since HHA points of view have not been documented, OTs do not know what support they need. Currently, OTs rely on a mix of theoretical knowledge and clinical experience to try to establish the needs of non-OTs collaborating with them [18]. This research aimed at exploring the support HHAs actually want to help them choose bathroom equipment for community-dwelling clients with bathing difficulties.

\section{Methods}

This study used a qualitative clinical research design [19-21], which is suitable for studying the crossdisciplinary relationships of HHAs and OTs as partners. Such a design makes it possible to consider underlying values and assumptions, and to direct the results toward clinical participants and policy makers.

This study was embedded in a large, ongoing research program on collaboration between non-OTs and home health OTs. Within this larger program initiated in 2007, a criterion validity study of the Préalables aux soins d'hygiène tool (French for "prerequisites for bathing care") was conducted [12,13]. This communication tool was developed between 1995 and 2005 by a group of clinical home-care occupational therapists with the aim of supporting HHAs in making recommendations for bathing equipment to communitydwelling clients who have bathing difficulties. This six-page document, written in French, is designed as a checklist involving an interview and observations in the home setting, guiding HHAs in selecting a place for bathing, the need for and type of grab bars, and bathing seat (Fig. 1). For the purpose of the criterion validity study, four HHAs conducted twenty-five assessments each using this tool with community-dwelling clients. All HHAs previously received a six hours of training by an OT (this paper's first author) to ensure proper understanding and use of the tool. During the decision-making process, the HHAs could at any time, and should have in specific circumstances, refer to a clinical OT on their interdisciplinary team for support.

\subsection{Participants}

In 2009, the four HHAs involved in the criterion validity study and eligible for the complementary inves- 


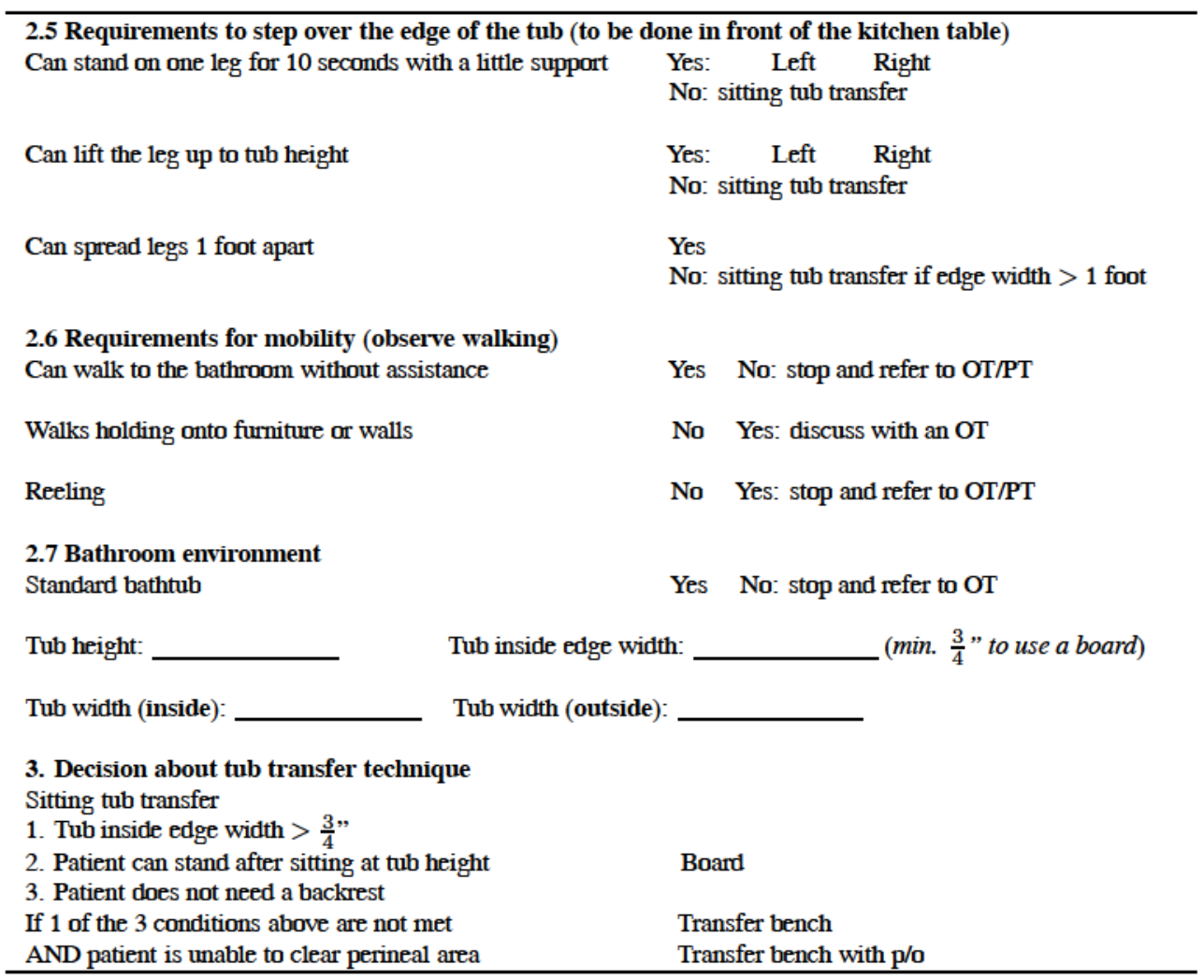

Fig. 1. Part of the "Préalables aux soins d'hygiène” translated from French (unpublished; available upon request at danielle@desnoyers.ca).

tigation were invited to share their experiences. Three of them (two men and one woman) agreed to participate. They were aged between 52 and 58 years, which is representative of the age group of HHAs in Quebec [14], and had 3 to 15 years of experience as HHAs.

\subsection{Data collection}

As recommended by Miller and Crabtree [19] to understand participant behavior, the three HHAs were first observed by an OT research assistant as they assessed a new client living at home or in a private residence for older adults. A new assessment allowed HHAs to relive their experiences, which had occurred more than a year before. Their observation enhanced the research assistant's understanding of how the HHAs performed their tasks and provided context for the subsequent data collection. Second, immediately after being observed, the HHAs were interviewed by the research assistant in a private room in their clinical settings. Individual interviews were selected over a focus group, since they yield more in-depth information and allow investigation of perceptions [22]. The research assistant used open- ended questions from an interview guide (Appendix 1), combined with questions based on relevant issues noted during observation. Finally, memos were used to facilitate reflexivity and research-team discussions.

The data-collection procedure was pretested with an HHA that selects bathing equipment but works in a different clinical setting. Moreover, we adopted an iterative approach throughout the qualitative research process $[19,21]$. Indeed, the research team listened to and discussed each field observation and interview, generating new questions, which enriched the remaining interviews. The interviews lasted respectively 52, 77, and 90 minutes, and were recorded and transcribed verbatim. After interviewing the three participants once, the research team determined that additional interviews with them were not necessary to get a thorough understanding of their perception, since no new themes were emerging. Still, since the number of participants was limited, the research team validated interpretation and language with two additional HHAs choosing bathing equipment in different HSSCs [23]. In fact, a written summary of the results were submitted to those two HHAs, followed by individual interviews seeking feed- 
back on accuracy of the account. Before observation and interviewing, each participant signed and received a copy of the consent form. The Research Ethics Committee of the Eastern Townships HSSC approved the research protocol.

\section{Data analyses}

As recommended under the qualitative clinical research design, a content analysis of the verbatim transcripts was realized using an editing style [19,21]. Therefore, the OT research assistant (who also acted as the observer and interviewer) approached the text as naively as possible, without a template. She searched for meaningful segments: cutting, pasting, and rearranging participant words. Actually, the analysis examined and connected units (segments of text that stood on their own and were related to the study's objective) to sort patterns and themes that, when reduced, revealed a representative interpretation. The frequency of appearance did not have a central influence on our content analysis. The coding of the three interviews was reviewed and enhanced by the first author and a consensus about the themes was reached by discussion with the research team. Throughout the analysis process, the research team met four times to challenge interpretation and audit decisions.

\section{Findings}

This qualitative clinical research highlighted four types of support needed by HHAs when choosing bathing equipment. The participants stated that HHAs performing such tasks should be selected based on specific attributes. Moreover, the participants described HHA support needs in terms of training, tools, and partnership.

\subsection{Required attributes for HHAs}

Participants believed that, generally speaking, HHAs have the attributes needed to be involved in selecting bathing equipment: "We are trained to bathe people safely. It's part of our training" (A2). "Since we already work with a lot of equipment in the home ... we have a bit of relevant experience" (A3). Actually, observation revealed that the participants carried themselves with confidence, adopting appropriate nonverbal communication strategies to initiate and maintain col- laboration with clients. Moreover, they believed their recognition would be enhanced by being involved in selecting equipment: "It strengthens us in our work, gives us another task to carry out so that we're not just there to give baths. We're not bath givers, washerwomen, and diaper changers. That's not our job" (A2). Indeed, participants felt "it's really a shame that we are shuttled off to one side sometimes. ... We can contribute, too" (A2).

Nevertheless, the participants recognized that an HHA who takes part in selecting equipment needs to have specific characteristics. The candidate should be motivated in accomplishing the task because "interest is a very big part of all that" (A3). Moreover, the HHA should have a minimum of a year or two of experience and be certified under the "Principles for Moving Clients Safely" program provided by the joint association for occupational health and safety in the area of social affairs (or, in French, Association paritaire pour la santé et la sécurité du travail du secteur affaires sociales) [24]. The program's objectives are to enable workers to: 1) safely carry out client transfers and positioning, 2) increase their skills in identifying dangerous situations and resolving them, and 3) communicate this information to the people responsible for occupational health and safety within their respective organizations [25]. Finally, participants thought that, to facilitate collaboration with OTs, HHAs should also be rigorous, observant, and open to criticism.

\subsection{Need for support}

Participants reported specific elements that would support HHAs involved in selecting bathing equipment. They break down into training, tools, and partnership.

\subsubsection{Training needs}

Even when HHAs have the attributes to be involved in choosing bathing equipment, the participants perceived HHAs should also have additional training. Participants considered the training should consist of "theory, in the beginning ... and why not have the OT accompany the HHA a time or two to make sure they are doing things right [and] role-playing ... the things we do work better than those we imagine" (A1).

Participants reported they would appreciate having comprehensive information about the equipment they could recommend. Indeed, they indicated the importance of having the correct vocabulary "so that we clearly are talking about the same thing" (A1). Observations also indicated that participants used different terminol- 
ogy when discussing about bathing assistive devices. Moreover, the participants felt that training should focus on a tool supporting HHAs in making decisions about bathing equipment.

\subsubsection{Need for a tool}

In this study, the participants guided their observations with the "prerequisites for bathing care" tool. The participants rated this tool positively [e.g. "It's well designed, really, it really works well, it's well structured, well made. It works really well all around" (A1)]. They considered that "a guide like the "prerequisites for bathing care' is indispensable because it gives us reference points" (A3). Such a tool enabled them to achieve the main objective of recommending equipment that "is best suited, that's going to be the safest for the client" (A2). Indeed, all participants completed the entire tool section, but a lot of movement back and forth was observed because, as it appeared to the observer/interviewer, the tool's structure lacked a thread of consistency.

Participants especially appreciated the fact that the tool helped them identify "simple cases" and stressed this as being very important for HHAs. Indeed, they want to be involved with clients for whom "it's easy to decide [because] we use just good common sense in making decisions" (A3). Yet "we don't have the knowledge or skills when it comes to diseases like Parkinson's or multiple sclerosis" (A2).

Regarding format, participants felt that some aspects of the "prerequisites for bathing care" should be modified (e.g. font size, landscape instead of portrait format, adding space for notes). Moreover, one of the participants carried a binder to protect the tool and provide a rigid surface to facilitate taking notes. Consultation of research files (e.g. artifacts) corroborated statements from participants about the need to add space for comments. According to the participants, the tool should allow HHAs to document their observations, questions, and selection in writing because "by keeping the tool with the recommendations, we have something that we can always refer back to" (A1). In addition, participants expressed the need for a user's manual for the tool. Furthermore, the manual should contain the rationale underlying the elements to be observed and how to proceed.

\subsubsection{Type of partnership}

In addition to specifications about the tool, participants raised the importance of having formal ongoing human support. In fact, one HHA stated that "the weak- est link in things like that [the tool] is the human factor. It's taking a response for granted instead of checking the question or the answer. Then there's nonchalance, skipping a section" (A1). Therefore, they considered that casual and frequent feedback on their individual performance would allow HHAs to share their experiences and keep their knowledge up-to-date. "Like with anything, you've got to try, then sit down and check if it was right or not. And, if it was right, you move on from there" (A1).

In addition, the participants indicated that HHAs want to be able to consult a team member designated beforehand, for "support. ... There has to be some kind of openness that way. Not just, say, leave the aides [HHAs] on their own with all that (A2)". "When I'm not sure, I ask the questions I have to, then I check with someone else. We're always there for the client's safety. I don't want to be responsible for an accident because I was negligent. That's really important to me (A3)."

While the participants considered that an OT should play this role, they felt that an experienced HHA could be a substitute, since OTs may not always be able to fulfill their need of support:

"The problem is that OTs are often just so busy that it's not a priority. The priority is much more for people with lots of problems, so, we wait. ...We don't have any choice. Sometimes, we're stuck in situations without an assessment [by an OT], so, we can only rely on ourselves. That's when we've [HHAs] got to deal with things that, from the HSSC's perspective, should be done by the OT (A2)."

Despite the fact that participants acknowledged their limits and underlined the importance of consulting an OT as needed, certain comments during the interviews and behaviors observed in the field suggested that HHAs are exceeding their mandate of selecting bathing or showering equipment:

"I think she [the client] appreciated the questions that I asked about how she felt, like when we talked about getting old .... I think it's important to stay in the here and now, to get an idea of how she functions on a daily basis. Of course, like with most people losing their independence when they get pretty old, there are often symptoms of depression. So, they need to be encouraged and get positive stimulus, because, otherwise, they wouldn't do anything. So, that's why I asked her if she had any children, if she saw them, if she went to the day room, if she went outdoors, I know that they have a small patio there. 
I can't do any more than that. She was also pleased with HSSC services (A2)."

\section{Discussion}

This research aimed at exploring the types of support HHAs need in choosing bathing equipment for community-dwelling clients with bathing difficulties. The qualitative clinical research revealed that participants felt that HHAs performing such tasks should be selected based on specific characteristics. Furthermore, they require training, a tool, and partnership with a designated OT. These results have clinical and work organizational implications that can be discussed further.

\subsection{Is the needed support available and optimal?}

First, even if the HHAs feel they have the basic knowledge needed to collaborate with OTs in selecting bathing equipment, they want formal training to support them prior to their involvement. A recent census conducted in 86 HSSCs in Quebec revealed that 92\% of the non-OTs selected to collaborate with OTs indeed undergo training [16]. Nevertheless, the format, length, and topics reported in this census did not match all the needs expressed by HHAs in our study. For example, hands-on experience during training is not addressed.

Second, the participants consider that the "Principles for Moving Clients Safely" training program should be a prerequisite for HHAs that select bathing equipment. The purpose of this program, based on an ergonomic frame of reference, is, however, to guide workers in making decisions that will enhance their own safety. Even though many of the principles taught (such as weight shift or body positioning) influence bathingequipment choices, it should be pointed out that, once adequate bathing equipment had been selected, many clients will not need bathing assistance from HHAs. Choosing bathing equipment based on an ergonomic perspective could therefore mislead the HHAs, since it is oriented towards the worker providing assistance, not towards the client with bathing difficulties that may or may not need human assistance. Therefore, it might be more appropriate to train HHAs in an occupational therapy frame of reference highlighting the central influence of client values and desires on occupational performance. This choice would allow coworkers HHAs and OTs - to use the same vocabulary when discussing bathing difficulties, another wish expressed by the participants.
Results also reinforced the urgency of adapting or developing a tool with good metrological qualities designed to guide HHAs involved in decisions concerning the need for technical assistance for bathing. Indeed, the need for a tool that could guide and document interventions, observations, and questions was clearly expressed by HHAs. As mentioned, clinical OTs in Quebec have designed at least 52 different "in-house" tools for non-OTs, with the "prerequisites for bathing care" being one of them [12]. To our knowledge, none of these tools answers all the needs expressed by HHAs. Such a mismatch can probably be explained by the fact that $62 \%$ of the tools were developed with no user input. For instance, the tools do not come with a user's manual and are not designed for taking notes that could eventually be helpful when discussing with an OT. Furthermore, HHAs would particularly appreciate a tool that includes comprehensive indications for identifying "simple cases".

Our participants also expressed the need for formal partnership with an OT, which is not consistently offered in HSSCs. In a work organization, an individual should not, however, be solely responsible for skill production and maintenance. Indeed, such competence depends on access to the network of knowledge and skills within the team [26]. Consequently, a reference person must be appointed to support HHAs, which inescapably means acting on organizational factors to warrant access to an OT. Our data support Cloutier et al.'s [27, 28], whose four case studies of HSSCs showed that the lack of access to occupational-therapy services impacted on the support, health, and work safety of HHAs in Quebec. Our findings are also coherent with studies investigating collaboration between nurses or supervisors and home health aides that shed light on their need of work support [29-31]. Considering that HHAs are frequently involved in selecting bathing equipment and that their needs of support might not be met in Quebec HSSCs, these results raise concerns about client security and safety.

\subsection{Clinical and work organizational implications}

In a recent legal and ethical analysis of access to home occupational-therapy services in Quebec, Carrier et al. [9] concluded that a HHA assigned a clinical task traditionally performed by an OT runs the risk of neither respecting the established boundaries nor detecting a client's potential for rehabilitation. Results from our study suggest that HHAs perceived their limited knowledge and recognized the importance of OT intervention 
in cases that were not simple. Yet, because of organizational constraints, OTs might not always be available to support the HHAs when needed, either by providing advices or assessing clients with complex clinical situations. Therefore, the lack of access to occupationaltherapy services might explain why HHAs seem to cross established boundaries.

Still, our observations and interviews suggested that the actions of HHAs involved in selecting bathing equipment went beyond the task's boundaries. Such actions, however, do not seem to be linked to a desire to override their assignment but rather to an interest in promoting healthy lifestyles, a role shared by all members of the interdisciplinary team. Moreover, Cloutier et al. [32] observed that the HHA's work included screening and social support tasks, which must be communicated to the case manager to prevent deterioration [27]. In addition, homecare workers advise family caregivers [33]. These HHA roles often go unnoticed [34]. Furthermore, Guichet and Hennion [34] explained that interdisciplinary teams dismiss the HHA role and knowledge, which are based on daily experience with clients rather than on education and training. Moreover, perhaps because most HHAs are women, Quebec HSSCs undervalue their work [35]. As previously illustrated by other authors [36,37], the results of our study indicate that HHAs seek recognition. Yet, providing support to HHAs implies acknowledging their contribution.

Moreover, collaborating with occupational therapists was perceived by our participants as an opportunity for advancement. Those findings are particularly relevant for homecare managers, since recognition and opportunities for advancement are two strategies identified for facing the challenge of recruiting and retaining home health aides [37-39]. Actually, according to Johnson and Noel [40], training and support enhance supportworker empowerment levels.

\section{Strengths and limitations}

The research design followed a participatory approach that considered values and assumptions, and emphasized results that are significant for clinical purposes. This study triangulated data from field observations and interviews, while fostering openness to emerging new themes as well as in-depth systematic data collection and analysis. Reliability was assured by recording and transcribing interviews, and with detailed descriptions of the methods. Like other qualita- tive studies, however, the results are time- and contextsensitive, and influenced by the researchers. Moreover, the study involved a limited number of participants, so saturation might not have been reached. Results and interpretation were taken back to additional HHAs, however, to verify the accuracy of the account. Still, if other HHAs could have been included, they might have highlighted different needs. Nevertheless, this study gives a voice to HHAs, who are often silent, marginalized, or absent from interdisciplinary-team decisions, even those directly affecting them. Moreover, it provides a valuable example of OT and non-OT collaboration at a time when service demands in numerous countries exceed the number of available qualified OTs, so population needs go unmet. Further research should be conducted, however, to support our evidence before undertaking policy changes regarding skill mixes in occupational therapy. For example, the client's perception of this organization model for selecting bathing equipment could be explored.

\section{Conclusion}

The purpose of this study was to find out what HHAs really need when working in collaboration with OTs in selecting bathing equipment for community-dwelling clients. Even if HHAs felt they had specific attributes, such as basic knowledge, they reported a need for training to acquire vocabulary about bathing difficulties and equipment as well as to learn how to use a tool that would guide and document their observations and help them identify "simple cases." Home health aides sought partnership with a designated OT, who would be available to answer questions and assess clients with complex clinical situations. According to data currently available, these needs might not be met in Quebec health-care institutions. This lack of support raises questions about patient safety and work efficiency.

\section{Acknowledgments}

We thank Professor Frances Gallagher for her contribution in planning the study.

The authors disclose receipt of the following financial support for the research and/or authorship of this article: Eastern Townships Health and Social Services Agency, Canadian Institutes of Health Research, Fonds de recherche en santé du Québec, Institut de recherche Robert-Sauvé en santé et sécurité du travail, AnÉIS program at the Université de Montréal, and the Canadian Foundation of Occupational Therapy. 


\section{References}

[1] Naik AD, Concato J, Gill TM. Bathing disability in community-living older persons: Common, consequential, and complex. J Am Geriatr Soc. 2004; 52(11): 1805-10.

[2] Canadian Institute for Health Information. Workforce Trends of Occupational Therapists in Canada, 2007. Ottawa(Ontario): Canadian Institute for Health Information, 2008.

[3] Tremblay L. L'ergothérapie dans les CLSC: État de situation. Ergothérapie express. 1995; 4(3): 98-103.

[4] Hébert M, Maheux B, Potvin L. Théories qui émergent du quotidien de la pratique communautaire de l'ergothérapie. Can J Occup Ther. 2002; 69(1): 31-9.

[5] Buchan J, Dal Poz MR. Skill mix in the health care workforce: Reviewing the evidence. Bull World Health Organ. 2002; 80(7): 575-80.

[6] Nancarrow S, Mackey $H$. The introduction and evaluation of an occupational therapy assistant practitioner. Aust Occup Ther J. 2005; 52(4): 293-301.

[7] Mackenzie M. Benefit or burden: introducing paraprofessional support staff to health visiting teams: The case of Starting Well. Health Soc Care Community. 2006; 14(6): 523-31.

[8] Stanmore E, Waterman H. Crossing professional and organizational boundaries: The implementation of generic rehabilitation assistants within three organizations in the northwest of England. Disabil Rehabil. 2007; 29(9): 751-9.

[9] Carrier A, Levasseur M, Mullins G. Accessibility of occupational therapy community services: A legal, ethical, and clinical analysis. Occup Ther Health Care. 2010; 24(4): 360-76.

[10] Nancarrow SA, Borthwick AM. Dynamic professional boundaries in the healthcare workforce. Sociol Health Illn. 2005; 27(7): 897-919.

[11] Cloutier E, David H, Ledoux E, Bourdouxhe M, Gagnon I, Ouellet F. Effects of government policies on the work of home care personnel and their occupational health and safety. Work. 2008; 30(4): 389-402.

[12] Guay M, Desrosiers J, Dubois M-F. Criterion validity of a home health aide's algorithm for recommending bathroom equipment. Can J Occup Ther. 2009; 76 Spec No: 246-56.

[13] Guay M, Desrosiers J, Dubois M-F. Does the clinical context affect the validity of bathroom recommendations made by home health aides? Int J Ind Ergon. 2010; 40(1): 82-9.

[14] Cloutier E, Bourdouxhe M, Ledoux É, David H, Gagnon I, Ouellet F, et al. Effets du statut d'emploi sur la santé et la sécurité au travail: le cas des auxiliaires familiales et sociales et des infirmières de soins à domicile au Québec. PISTES. 2005; 7(2): 1-16

[15] Cloutier E, David H, Ledoux É, Bourdouxhe M, Teiger C, Gagnon I, et al. Importance de 1'organisation du travail comme soutien aux stratégies protectrices des AFS et des infirmières des services de soins et de maintien à domicile. IRSST: 2006. Report No: RR-453.

[16] Guay M, Dubois M-F, Desrosiers J, Robitaille J, Charest J. The use of skill mix in homecare occupational therapy with patients with bathing difficulties. IJTR. 2010; 17(6): 300-8.

[17] Ordre des ergothérapeutes du Québec. Participation du personnel non-ergothérapeute à la prestation des services d'ergothérapie: Lignes directrices. Montréal (Québec): Ordre des ergothérapeutes du Québec, 2005

[18] Doumanov P, Rugg S. Clinical reasoning skills of occupational therapists and support staff: a comparison. IJTR. 2003; 10(5): 195-203.

[19] Miller WL, Crabtree BF. Clinical research - a multimethod typology and qualitative roadmap. In: Crabtree BF, Miller
WL, editors. Doing qualitative research. 2nd ed. Thousand Oaks (CA): Sage Publications, Inc; 1999, pp. 3-30.

20] Miller WL, Crabtree BF. Clinical Research. In: Denzin NK, Linclon YS, editors. Handbook of qualitative research. 2nd ed. Thousand Oaks (CA): Sage Publications, Inc; 2000, pp. 60731.

[21] Miller WL, Crabtree BF. Clinical Research. In: Denzin NK, Linclon YS, editors. Strategies of qualitative inquiry. 2nd ed. Thousand Oaks (CA): Sage Publications, Inc; 2003, pp. 397434.

[22] Creswell JW, Plano Clark VL. Designing and conducting mixed methods research. Thousands Oaks (CA): Sage Publications, 2007.

[23] Creswell JW. Qualitative inquiry and research design: Choosing among five approaches. 2nd ed. Thousand Oaks (CA): Sage Publications, Inc, 2007.

[24] Association paritaire pour la santé et la sécurité du travail du secteur affaires sociales. Guide de gestion du programme de formation PDSB par l'établissement. Montréal (Québec): Association paritaire pour la santé et la sécurité du travail du secteur affaires sociales, 2007.

[25] Berthelette D, Leduc N, Bilodeau H, Durand M-J, Faye C, Loignon C, et al. Analyse d'un programme de formation visant la prévention primaire des maux de dos chez le personnel soignant des centres hospitaliers du Québec. Montréal (Québec): Institut Robert-Sauvé en santé et sécurité au travail; 2006. Report No: R-452.

[26] Le Boterf G. Construire les compétences individuelles et collectives. 2e ed. Paris: Éditions d'organisation, 2002.

[27] Cloutier E, David H, Ledoux É, Bourdouxhe M, Teiger C, Gagnon I, et al. Importance de l'organisation du travail comme soutien aux stratégies protectrices des AFS et des infirmières des services de soins et de maintien à domicile. IRSST, 2005. Report No: R-429.

[28] Cloutier E, David H, Teiger C. Agir sur les conditions de travail des auxiliaires de vie: croiser les approches. Travail et emploi. 2003; 94: 75-84.

[29] Beschle JC, Beggs CM, Russell GE. Interviews with home health aides caring for people with AIDS. Home Healthc Nurse. 1995; 13(6): 20-4.

[30] Buelow JR, Winburn K, Hutcherson J. Job satisfaction of home care assistants related to managerial practices. Home Health Care Serv Q. 2009; 17(4): 59-71.

[31] Devlin M, McIlfatrick S. Providing palliative and end-of-life care in the community: the role of the home-care worker. Int J Palliat Nurs. 2010; 16(4): 195-203.

[32] Cloutier E, David H, Prévost J, Teiger C. Importance of experience for older home care workers in facing up to the constraints of work. Exp Aging Res. 1999;25(4):405-10.

[33] Roelands M, Van Oost P, Depoorter A, Verloo H. Knowing the diagnosis and counselling the relatives of a person with dementia: The perspective of home nurses and home care workers in Belgium. Health Soc Care Community. 2005; 13(2): 112-24.

[34] Guichet F, Hennion A. Vivre avec Alzheimer, vivre avec un "Alzheimer". Gerontol Soc. 2009(128/129): 117-28.

[35] Cognet M. Les femmes, le service et le don. Cahiers de recherche sociologique. 2002; 37: 51-77.

[36] Gagnon I, David H, Cloutier E, Ouellet F, Ledoux É, Bourdouxhe $\mathrm{M}$, et al. Organisation du travail et développement des stratégies protectrices: Cas d'auxiliaires sociales et familiales de services publics de maintien à domicile. Gerontol Soc. 2003; 107: 131-48. 
[37] Ashley A, Butler SS, Fishwick N. Home care aides' voices from the field: Job experiences of personal support specialists. Home Healthc Nurse. 2010; 28(7): 399-405.

[38] Brannon D, Barry T, Kemper P, Schreiner A, Vasey J. Job perceptions and intent to leave among direct care workers: Evidence from the better jobs better care demonstrations. Gerontologist. 2007; 47(6): 820-9.

[39] Jorgensen D, Parsons M, Reid MG, Weidenbohm K, Parsons J, Jacobs $S$. The providers' profile of the disability support workforce in New Zealand. Health Soc Care Community. 2009; 17(4): 396-405.

[40] Johnson CS, Noel M. Level of empowerment and health knowledge of home support workers providing care for frail elderly. Home Health Care Serv Q. 2007; 26(3): 61-80.
Appendix 1: Examples of questions from the semi-structured qualitative interview

- Generally speaking, what helped you select bathing equipment for this person?

* What helped you during the home visit?

* What could have been useful to you other than the tool?

- In your opinion, what kind of support should be provided to a home health aide involved in selecting bathing equipment?

- What guides your observations when selecting bathing equipment?

- Other than those pertaining to the tool, what elements would help you in selecting bathing equipment? 